\title{
Photochemical degradation of environmentally persistent perfluorooctanoic acid (PFOA) in the presence of Fe(III)
}

\author{
Yuan Wang ${ }^{\text {a,b,c }}$, Peng Yi Zhang ${ }^{\text {c,* }}$, Gang Pan ${ }^{\text {a }}$, Hao Chen ${ }^{\text {a }}$ \\ ${ }^{a}$ State Key Laboratory of Environmental Aquatic Chemistry, Research Center for Eco-Environmental Science, \\ Chinese Academy of Science, Beijing 100085, China \\ ${ }^{\mathrm{b}}$ Graduate School of the Chinese Academy of Sciences, Beijing 100039, China \\ ${ }^{\mathrm{c}}$ Department of Environment Science and Engineering, Tsinghua University, Beijing 100084, China
}

Received 28 August 2007

\begin{abstract}
Environmentally persistent and bioaccumulative perfluorooctanic acid (PFOA) was difficult to be decomposed under the irradiation of $254 \mathrm{~nm}$ UV light. However, in the presence of $80 \mu \mathrm{mol} / \mathrm{L} \mathrm{Fe}(\mathrm{III}), 80 \%$ of PFOA with initial concentration of $48 \mu \mathrm{mol} / \mathrm{L}$ ( $20 \mathrm{mg} / \mathrm{L}$ ) was effectively degraded and $47.8 \%$ of fluorine atoms in PFOA molecule were transformed into inorganic fluoride ion after $4 \mathrm{~h}$ reaction. Shorter chain perfluorocarboxylic acids bearing $\mathrm{C}_{3}-\mathrm{C}_{7}$ and fluoride ion were detected and identified by LC/MS and IC as the degradation products in the aqueous solution. It was proposed that complexes of PFOA with Fe(III) initiated degradation of PFOA irradiated with $254 \mathrm{~nm}$ UV light.
\end{abstract}

(C) 2007 Peng Yi Zhang. Published by Elsevier B.V. on behalf of Chinese Chemical Society. All rights reserved.

Keywords: Perfluorooctanoic acid; Iron(III); Photochemical degradation; $254 \mathrm{~nm}$ UV light

In recent years, trace amounts of perfluorooctanic acid (PFOA) and perfluorooctanesulfonic acid (PFOS) have been widely found in many environmental media [1]. Their persistent nature and wide occurrence present a concern for possible effects on environment and human. In 2002, OECD issued the hazard assessment of PFOS and its salts [2]. And in 2003, U.S. EPA issued a preliminary risk assessment of the developmental toxicity associated with exposure to PFOA and its salts [3]. Further in 2006, U.S. EPA launched a global stewardship program to reduce PFOA emissions and its presence in products by $95 \%$ by 2010 , aiming for complete elimination by 2015 [4]. Thus, to abate the potential harm of these compounds to the environment and human health, it is necessary to develop effective methods to degrade these compounds into harmless species under mild conditions.

These compounds are quite stable due to the strong C-F bonds and their natural decomposition pathways are unknown. Recently, Hori et al. [5] reported that PFCAs with various carbon chains were effectively degraded under 220-460 nm UV-vis light irradiation by using a homogeneous photocatalysttungstic heteropolacid $\left(\mathrm{H}_{3} \mathrm{PW}_{12} \mathrm{O}_{40} \cdot \mathrm{H}_{2} \mathrm{O}\right)$ or by using persulfate $\left(\mathrm{S}_{2} \mathrm{O}_{8}{ }^{2-}\right)$ as a photochemical oxidant. On the other hand, Chen and Zhang [6] investigated the influences of oxidant $\left(\mathrm{K}_{2} \mathrm{~S}_{2} \mathrm{O}_{8}\right)$, reaction atmospheres $\left(\mathrm{O}_{2}, \mathrm{~N}_{2}\right)$ and UV wavelength $(185 \mathrm{~nm}$ and $254 \mathrm{~nm}$ light) on PFOA decomposition. These authors argued that PFCAs were oxidized by the photoexcited

\footnotetext{
* Corresponding author.

E-mail address: zpy@mail.tsinghua.edu.cn (P.Y. Zhang).
} 
species $\left(\left[\mathrm{PW}_{12} \mathrm{O}_{40}\right]^{3-}\right.$ or $\left.\mathrm{SO}_{4}{ }^{--}\right)$, i.e. one electron was transferred from PFCAs to the photoexcited species. Moriwaki et al. [7] also studied the sonochemical decomposition of PFOA and PFOS under air or argon atmosphere. They suggested that the cavitation phenomena produced by ultrasonic irradiation made the PFOS and PFOA molecules pyrolyzed at the interfacial region between the calvitation bubbles and the bulk solution.

Iron is the most abundant transition metal in Earth. The complexes of Fe(III) with simple carboxylic acids exhibit obvious photochemical behavior [8]. In the present study, we demonstrated the efficient decomposition of PFOA under $254 \mathrm{~nm}$ UV light in the presence of Fe(III).

\section{Experimental}

The photochemical reactions were conducted in a glass cylinder with inner diameter $55 \mathrm{~mm}$. A low-pressure mercury lamp $(23 \mathrm{~W})$ emitting with $254 \mathrm{~nm}$ was placed in the center of the reactor with two-layer quartz tube protection (external diameter $25 \mathrm{~mm}$, internal diameter $23 \mathrm{~mm}$ ). Water was filled in jacket between two quartz tubes to filter any $185 \mathrm{~nm}$ light from the UV lamp. In a typical run, $500 \mathrm{~mL}$ mixture aqueous solution of PFOA $48 \mu \mathrm{mol} / \mathrm{L}$ and $\mathrm{Fe}_{2}\left(\mathrm{SO}_{4}\right)_{3}$ with different ferric concentration was filled into the reactor. Oxygen was bubbled into the reaction through a porous glass plate with a flow rate at $100 \mathrm{~mL} \mathrm{~min}^{-1}$ during the reaction. The reactions were carried out at room temperature with a cooling water jacket around the reactor. PFOA and the degradation products were analyzed by LCMS (ZQ 4000, Waters, USA). Fluoride ion $\left(\mathrm{F}^{-}\right)$was measured by ion chromatography (761 compact IC, Metrohm). Degradation ratio and defluorination ratio were calculated as follows:

$$
\begin{aligned}
& \text { degradation ration }=100 \times \frac{C_{0}-C}{C_{0}} \\
& \text { defluorination ratio }=100 \times \frac{C_{\mathrm{F}^{-}}}{C_{0} \times 15}
\end{aligned}
$$

where $C_{0}(\mu \mathrm{mol} / \mathrm{L})$ is the initial concentration of PFOA, $C(\mu \mathrm{mol} / \mathrm{L})$ is the concentration of PFOA at sometime, $C_{\mathrm{F}^{-}}(\mu \mathrm{mol} / \mathrm{L})$ is the concentration of fluoride ion and the factor 15 corresponds to the number of fluorine atoms in a PFOA molecule.

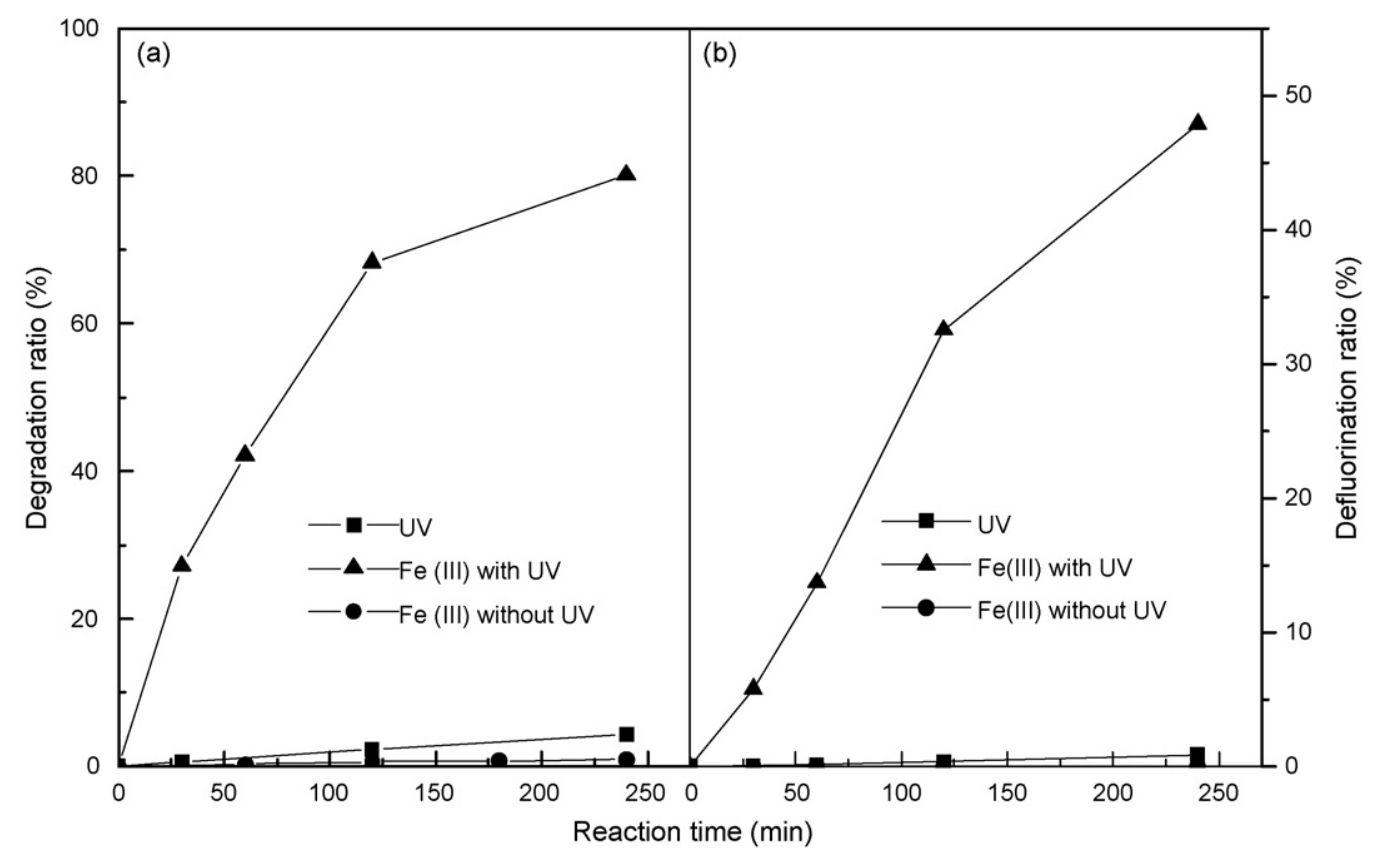

Fig. 1. (a) Degradation ratio and (b) defluorination ratio of PFOA with reaction time. 


\section{Results and discussion}

Fig. 1a showed the time dependence of degradation of PFOA under different reaction conditions. The direct photolysis of PFOA under $254 \mathrm{~nm}$ UV light was very slow and negligible. There was also no perceptible change to PFOA when $\mathrm{Fe}_{2}\left(\mathrm{SO}_{4}\right)_{3}$ was added into reactive solution without UV irradiation. However, PFOA was efficiently degraded under $254 \mathrm{~nm}$ UV light in the presence of $80 \mu \mathrm{mol} / \mathrm{L} \mathrm{Fe}(\mathrm{III})$, about $80 \%$ PFOA was decomposed within $4 \mathrm{~h}$ reaction. The reaction followed pseudo-first-order kinetics and the half-life time of PFOA degradation was about $100 \mathrm{~min}$. And accompanying with the decomposition of PFOA, fluoride ion was detected and increased with the reaction time. The defluorination ratio was up to $47.8 \%$ (Fig. 1b) within $4 \mathrm{~h}$ reaction, i.e. averagely 7.2 of 15 fluorine atoms in PFOA molecule were transformed into inorganic fluoride ion.

In addition, short-chain perfluorocarboxylic acids bearing $\mathrm{C}_{3}-\mathrm{C}_{7}$ perfluoroalkyl groups, such as pentafluoropropionic acid $\left(\mathrm{C}_{2} \mathrm{~F}_{5} \mathrm{COOH}\right)$, perfluorobutyric acid $\left(\mathrm{C}_{3} \mathrm{~F}_{7} \mathrm{COOH}\right)$, perfluoropentanoic acid $\left(\mathrm{C}_{4} \mathrm{~F}_{9} \mathrm{COOH}\right)$, perfluorohexanoic acid $\left(\mathrm{C}_{5} \mathrm{~F}_{11} \mathrm{COOH}\right)$, and perfluoroheptanoic acid $\left(\mathrm{C}_{6} \mathrm{~F}_{13} \mathrm{COOH}\right)$, were identified by LC/MS as the degradation products according to the mass spectra and retention time (Fig. 2). Small amount of trifluoroacetic acid $\left(\mathrm{CF}_{3} \mathrm{COOH}\right)$ was also detected. The degradation products are the same as those reported by other researchers [5-7]. Concentrations change of these short-chain perfluorocarboxylic acids during the reaction were shown in Fig. 3a. In the present experiment, these short-chain perfluorocarboxylic acids in the reaction solution were gradually accumulated and increased during $4 \mathrm{~h}$ reaction time.

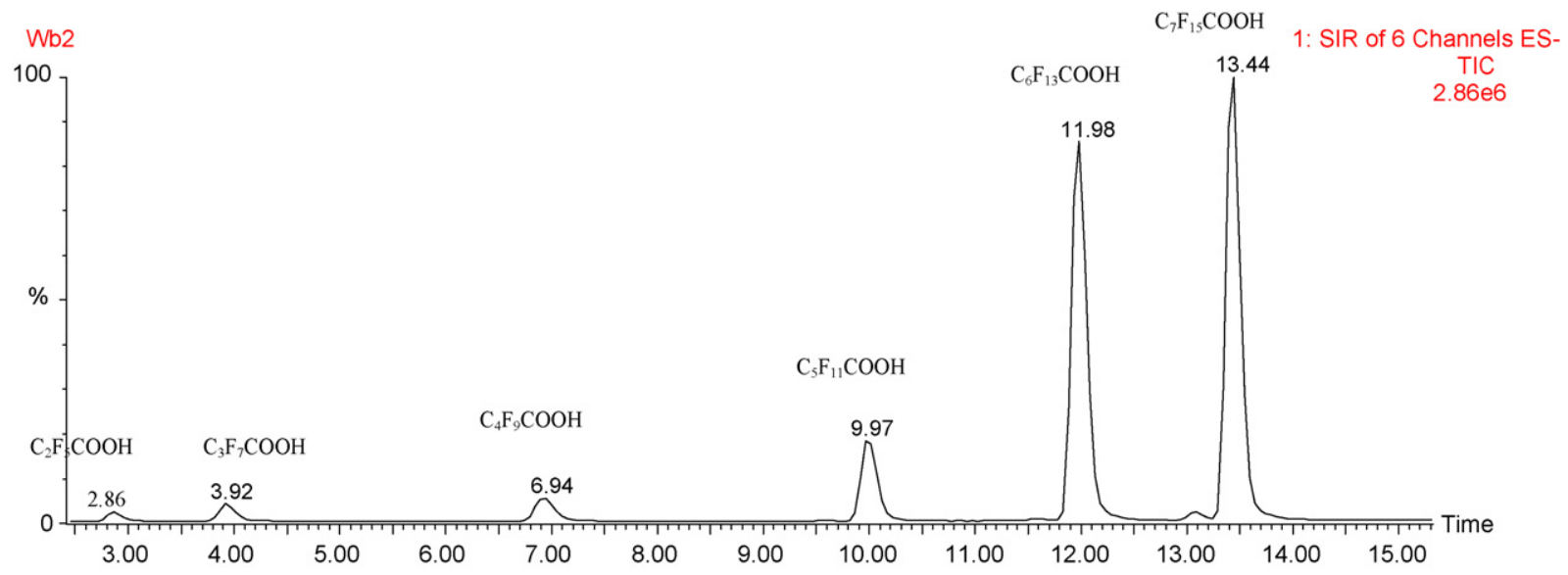

Fig. 2. TIC spectra of PFOA and its short chain degradation products after $4 \mathrm{~h}$ reaction.
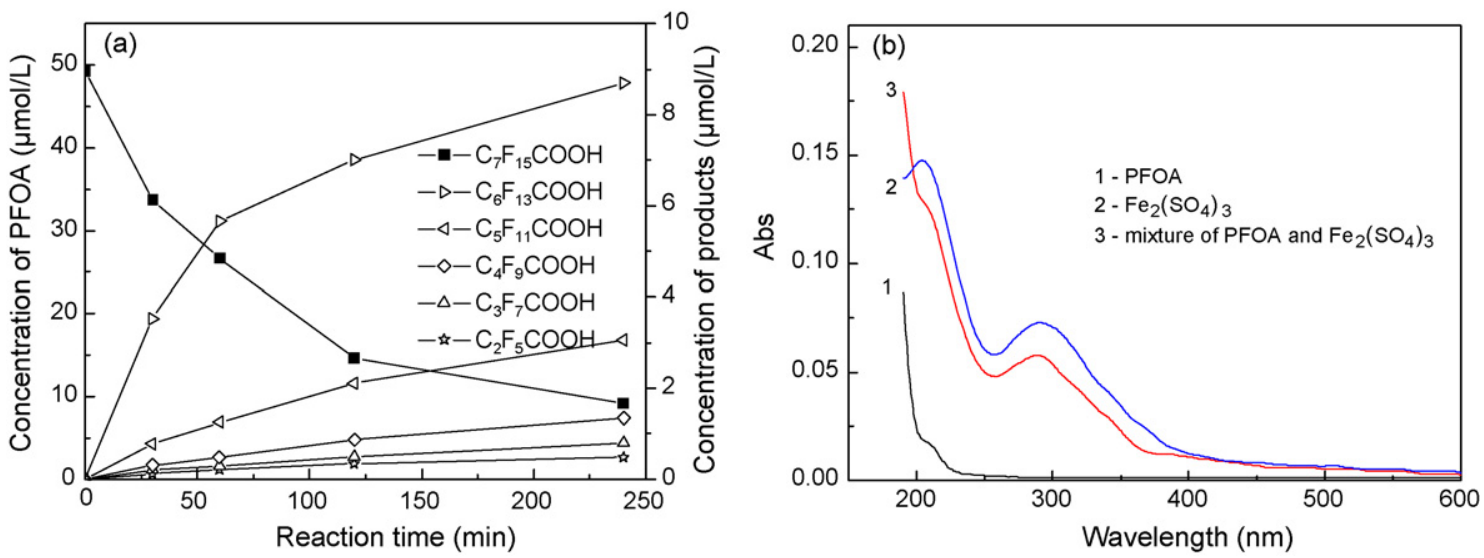

Fig. 3. (a) Changes of the concentration of PFOA and its intermediate products and (b) UV-vis spectra of PFOA $(48 \mu \mathrm{mol} / \mathrm{L}), \mathrm{Fe}_{2}(\mathrm{SO} 4)_{3}(50 \mu \mathrm{mol} /$ $\mathrm{L})$ and mixture solution of PFOA and $\mathrm{Fe}_{2}\left(\mathrm{SO}_{4}\right)_{3}$. 
For the mechanism of photochemical decomposition of PFOA in the presence of Fe(III), it was proposed that a complex of PFOA and Fe(III) could first be formed, which could effectively absorb $254 \mathrm{~nm}$ UV light (Fig. 3b). Then excited by the $254 \mathrm{~nm}$ UV light, the complexes were decarboxylated and simultaneously hydrolyzed, and shorterchain perfluorocarboxylic acids and fluoride ion formed in the solution. And that the reaction was carried out under oxygen atmosphere, which suggested oxygen could play an important role either in the PFOA decomposition step or in the transformation between Fe(III) and Fe(II). The transformation could, in turn, induce the degradation of PFOA. Based on the above consideration, the detailed research of degradation mechanism is conducting in our group.

\section{Acknowledgments}

This work was financially supported by the National Natural Science Foundation of China (No. 20577026) and National Basic Research Program of China (No. 2007CB613303).

\section{References}

[1] (a) C.A. Moody, J.W. Martin, W.C. Kwan, D.C.G. Muir, S.A. Mabury, Environ. Sci. Technol. 36 (4) (2002) 545;

(b) M. Shoeib, T. Harner, B.H. Wilford, K.C. Jones, J. Zhu, Environ. Sci. Technol. 39 (17) (2005) 6599;

(c) H. Nakata, K. Kannan, T. Nasu, H.-S. Cho, E. Sinclair, T.A. akemura, Environ. Sci. Technol. 40 (16) (2006) 4916;

(d) E. Sinclair, K. Kannan, Environ. Sci. Technol. 40 (5) (2006) 1408.

[2] Organization for Economic Co-operation and Development ENV/JM/RD (2002) 17.

[3] U.S. Environmental Protection Agency, Office of Pollution Prevention and Toxics Risk Assessment Division April 10, 2003.

[4] Supporting Information is also available electronically on the U.S. Environmental Protection Agency Web site, http://www.epa.gov/oppt/pfoa/ pfoastewardship.htm.

[5] (a) H. Hori, E. Hayakawa, H.E. inaga, S. Kutsuna, K. Koike, T. Ibusuki, H. Kiatagawa, R. Arakawa, Environ. Sci. Technol. 38 (22) (2004) 6118;

(b) H. Hori, A. Yamamoto, E. Hayakawa, S. Taniyasu, N. Yamashita, S. Kutsuna, H. Kiatagawa, R. Arakawa, Environ. Sci. Technol. 39 (7) (2005) 2383;

(c) H. Hori, A. Yamamoto, S. Kutsuna, Environ. Sci. Technol. 39 (19) (2005) 7692.

[6] J. Chen, P. Zhang, Water Sci. Technol. 54 (11) (2006) 317.

[7] H. Moriwaki, Y. Takagi, M. Tanaka, K. Tsuruho, K. Okitsu, Y. Maeda, Environ. Sci. Technol. 39 (9) (2005) 3388.

[8] T.D. Waite, O. Hutzinger, The Handbook of Environmental Chemistry, Vol. 2, Part M, 2005, p. 266. 